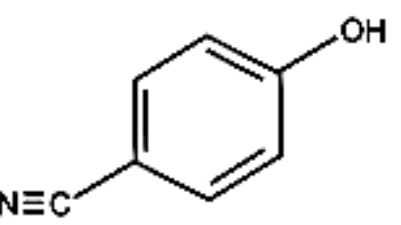

iii)

iv)

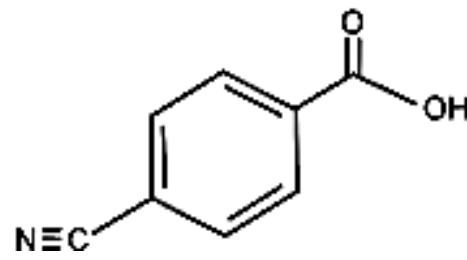

FIG. 3. Molecular structures of (i) acetonitrile, (ii) 4-cyanophenol, (iii) 1pentanenitrile, and (iv) 4-cyanobenzoic acid.

solute in polymer indicated that strong affiliation between polymers and solutes, which leads to a strong partitioning effect, would actually slow down the diffusion process. The attraction force between the solution and the matrix becomes the molecular friction for the diffusion. Furthermore, those molecules that partition in the hair are larger than acetonitrile and 1-pentanenitrile. The size of the molecule could also contribute to the effect on the speed of diffusion as well as the molecular structure, like the difference between aliphatic hydrocarbons versus aromatic hydrocarbons.

This brief study has illustrated the potential of this novel approach to investigate diffusion of solutes into micro fibers, such as human hair, in situ. The system could be further optimized by noting that a large area of the image was redundant in the analysis. A smaller FPA detector (e.g., a $32 \times$ 32 array) would have collected the same information for a much shorter measurement time, and hence, a better temporal resolution. On the other hand, the large area measured could have been utilized for high throughput measurements by arranging several cross-sections of hair in the image field of view. Diffusion studies of different hair types or simply a larger number of repeat measurements can be carried out in parallel. Nevertheless, the idea of using this approach to study the diffusion of solutes in hair has been demonstrated.

In summary, we have demonstrated the potential of in situ FT-IR spectroscopic imaging to study the diffusion of chemicals across the hair cross-section. All spectra were measured simultaneously, enabling the study of dynamic systems. The study of the diffusion of four model chemicals, acetonitrile, 1-pentanenitrile, 4-cyanophenol, and 4-cyanobenzoic acid, into hair cross-sections has been demonstrated. 4Cyanophenol and 4-cyanobenzoic acid require a much longer time to complete the diffusion process owing to their relatively larger molecular sizes and the possibility of the formation of $\mathrm{H}-$ bonds with the polar groups of the hair proteins. It is possible to further optimize this study by using a smaller FPA array for a better temporal resolution or arranging more hair crosssections into the field of view of the detector for high throughput studies. The demonstrated in situ approach can be applied to a wide range of diffusion studies, not limited to hair cross-sections but applicable to any biological tissues. ${ }^{19}$

1. A. Kuzuhara and T. Hori, J. Appl. Polym. Sci. 97, 65 (2005).

2. S. Ruetsch, B. Yang, and Y. Kamath, J. Cosmetic Sci. 54, 379 (2005).

3. C. L. Gummer, J. Cosmetic Sci. 52, 265 (2001).

4. S. F. DeLauder and D. A. Kidwell, Forensic Sci. Int. 107, 93 (2000).

5. L. E. Jurdana, K. P. Ghiggino, I. H. Leaver, C. G. Barraclough, and P. Coleclarke, Appl. Spectrosc. 48, 44 (1994).

6. A. Kuzuhara and T. Hori, Biopolymers 79, 324 (2005).

7. T. Gao and A. Bedell, J. Cosmetic Sci. 52, 103 (2001).

8. J. C. Oxley, J. L. Smith, L. J. Kirschenbaum, K. R. Shinde, and S. Marimganti, J. Forensic Sci. 50, 826 (2005).

9. C. R. Borges, D. G. Wilkins, and D. E. Rollins, J. Anal. Toxicol. 25, 221 (2001).

10. M. H. Slawson, D. C. Wilkins, and D. E. Rollins, J. Anal. Toxicol. 22, 406 (1998).

11. E. N. Lewis, P. J. Treado, R. C. Reeder, G. M. Story, A. E. Dowrey, C. Marcott, and I. W. Levin, Anal. Chem. 67, 3377 (1995).

12. C. M. Snively, S. Katzenberger, G. Oskarsdottir, and J. Lauterbach, Opt. Lett. 24, 1841 (1999).

13. T. Ribar, R. Bhargava, and J. L. Koenig, Macromolecules 33, 8842 (2000).

14. S. G. Kazarian and K. L. A. Chan, Macromolecules 36, 9866 (2003).

15. D. W. Rafferty and J. L. Koenig, J. Contr. Rel. 83, 29 (2002).

16. A. Gupper and S. G. Kazarian, Macromolecules 38, 2327 (2005).

17. K. L. A. Chan, S. G. Kazarian, A. Mavraki, and D. R. Williams, Appl. Spectrosc. 59, 149 (2005).

18. F. Briki, B. Busson, L. Kreplak, P. Dumas, and J. Doucet, Cell. Mol. Bio. 46, 1005 (2000).

19. S. G. Kazarian and K. L. A. Chan, Biochim. Biophys. Acta 1758, 858 (2006).

\section{Discrimination of Transgenic and Conventional Soybean Seeds by Fourier Transform Infrared Photoacoustic Spectroscopy}

\begin{abstract}
A. R. L. CAIRES, * M. R. O. TEIXEIRA, Y. R. SÚAREZ, L. H. C. ANDRADE, and S. M. LIMA

Grupo de Óptica Aplicada, Universidade Federal da Grande Dourados - UFGD, C.P. 533, 79804-970, Dourados, MS, Brazil (A.R.L.C.); Centro de Pesquisa Agropecuária do Oeste Embrapa - CPAO, C.P. 661 79804-970, Dourados, MS, Brazil (M.R.O.T.); Laboratório de Ecologia, Centro Integrado de Análise e Monitoramento Ambiental, Universidade Estadual de Mato Grosso do Sul, C.P. 351, 79804-970, Dourados, MS, Brazil (Y.R.S.); and Grupo de Espectroscopia Óptica e Fototérmica, Centro Integrado de Análise e Monitoramento Ambiental, Universidade Estadual de Mato Grosso do Sul - C.P. 351, 79804-970, Dourados, MS, Brazil (L.H.C.A., S.M.L.)
\end{abstract}

Index Headings: Fourier transform-infrared spectroscopy; FT-IR spectroscopy; Photoacoustics; PAS; Soybeans; Genetic modification; Canonical discriminant analysis.

\section{INTRODUCTION}

The number of products derived from genetically modified organisms (GMO) available in the market has been increasing

Received 6 July 2007; accepted 18 June 2008

* Author to whom correspondence should be sent. E-mail: andercaires@ufgd. edu.br. 
in the last decade. However, the suspicion that these products are not safe for consumers has led public agencies in several countries to establish legislation requiring mandatory labeling of GMO foods and food ingredients.

There are several common methods for GMO identification and classification: immunoassay TRAIT test for the specific detection of Roundup Ready ${ }^{\circledR}$ soybean; ${ }^{1}$ Western blot; ${ }^{2}$ enzyme-linked immunosorbant assay (ELISA) analyses based on protein information; ${ }^{3}$ and polymerase chain reaction (PCR) analyses based on DNA information.,5 Although these methods can be combined to quantify GMO in foods, in our view, the scientific community needs to test other methods for detection and quantification of GMO. Besides, these methods must also distinguish between GMO and non-GMO.

In recent years, alternative methods for identification of GMO using rapid and inexpensive analyses have been developed, such as optical spectroscopy. Roussel et al. ${ }^{6}$ applied near-infrared (NIR) spectroscopy to distinguish Roundup Ready $^{\mathrm{TM}}$ from conventional soybeans. NIR spectroscopy and Fourier-transform infrared (FT-IR) spectroscopy were independently applied to plants for the discrimination of genomics DNA from different genotypes. ${ }^{7}$ In the case of FT-IR spectroscopy, when coupled with a photoacoustic (PAS) cell, it is possible to determine the mode of vibration of several kinds of materials, including plants $^{8}$ and foods. ${ }^{9}$ Several studies demonstrated that FT-IR-PAS is a rapid and nondestructive technique and a powerful analytical tool for providing information about the mid-infrared absorption spectra. ${ }^{10,11} \mathrm{It}$ involves direct measurement of the acoustic signal produced by the sample after the absorbed infrared radiation is converted into heat by the sample surface. ${ }^{12,13}$

The objective of the present Note is to show that the FT-IRPAS technique could be a sensible method for distinguishing between transgenic and non-transgenic soybeans when combined with canonical discriminant analyses (CDA). The methodology was applied to two commercial pairs of soybean seeds extensively used in Brazil.

\section{MATERIALS AND METHODS}

Soybean Samples. Glyphosate, the active ingredient of Roundup $^{\circledR}$, is one of the most widely used herbicides with lower environmental impact. ${ }^{14}$ It functions by inhibiting the activity of the enzyme 5-enolpyruvylshiki-mate-3-phosphate synthase (EPSPS). The EPSPS enzyme is critical in the metabolic pathway leading to development of essential aromatic amino acids. ${ }^{15}$ The inhibition of EPSPS by glyphosate blocks the production of the amino acids and results in plant death. An alternate form of the EPSPS enzyme that is not inhibited by glyphosate, called CP4-EPSPS, was discovered in the Agrobacterium tumefaciens. This alternative gene was modified by adding a promoter that is recognized by plants and inserted into soybean to create the Roundup Ready ${ }^{\circledR}$ (RR) soybean. Since this modified RR soybean contains the CP4-EPSPS enzyme, it will not be killed by glyphosate. ${ }^{16}$

Four varieties of soybean were analyzed in this study: $B R S$ 133, BRS 245RR, EMBRAPA 59, and BRS 244RR, where BRS 133 and EMBRAPA 59 are conventional soybeans and BRS $245 R R$ and $B R S 244 R R$ are transgenic ones. The $B R S 245 R R$ variety originates from genetic modification of the $B R S 133$ by the introduction of the Roundup Ready ${ }^{\circledR}$ gene and the $B R S$ $244 R R$ variety originates from genetic modification of the

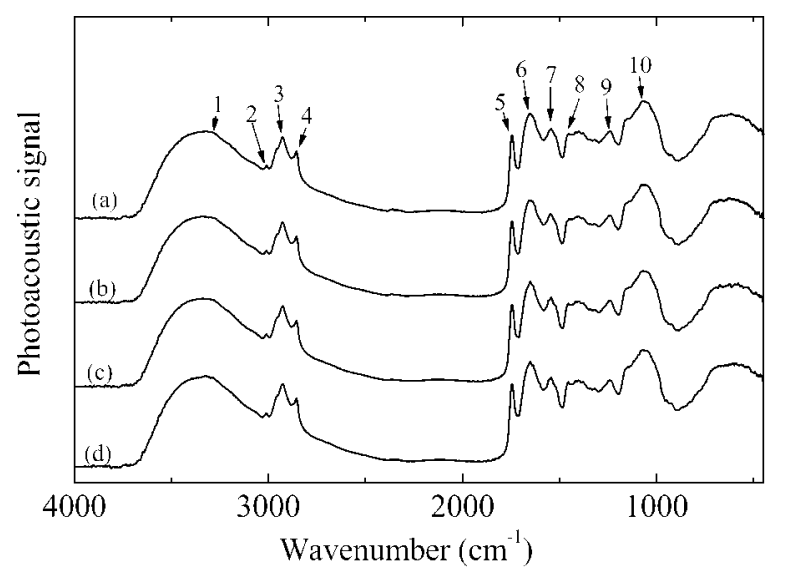

FIG. 1. Average FT-IR-PAS of (a) transgenic $B R S 244 R R,(\boldsymbol{b})$ conventional EMBRAPA 59, (c) transgenic BRS 245RR, and (d) conventional BRS 133 soybean seeds. The spectra were vertically translated for ease of visualization.

EMBRAPA 59 variety by introduction of the same gene. The four soybean seeds used in this investigation were developed by Brazilian Agricultural Research Corporation (EMBRAPA) and produced in the same environments. These varieties are widely used in several regions of Brazil.

For spectroscopic measurements, 200 (50 of each variety) soybean seeds were selected and cut in half, along the hilum, in order to analyze the superficial region of the cotyledon, without any special sample preparation. Only one half of each seed was used in our experimental procedure.

Fourier Transform Infrared Photoacoustic Spectroscopy. Mid-infrared spectroscopy was carried out with a ThermoNicolet Nexus 670 Spectrophotometer combined with a Photoacoustic detector (MTEC-300). The spectrophotometer was purged with pure nitrogen gas in order to eliminate $\mathrm{CO}_{2}$ and water vapor during the experiment. The photoacoustic cell was purged with helium during all acquisitions. First, a reference spectrum was obtained with carbon black to normalize the sample spectra. For each variety, 50 samples were selected, and for each sample, 64 scans were realized. Spectra were obtained between 4000 and $400 \mathrm{~cm}^{-1}$ with $8 \mathrm{~cm}^{-1}$ resolution. The data were acquired by the Omnic Software that accompanies the commercial spectrophotometer used in this work.

Statistical Analysis. In order to quantify the differences in the analyzed soybean varieties, canonical discriminant analysis (CDA) was carried out for each obtained spectra. For this step, the wavenumbers of the peaks are used as factor (explanatory variables) and their intensities are used as response variables. The stepwise procedure was utilized to obtain a minimum model predicting the differentiation between varieties. This method was utilized to find the linear combinations of variables that maximize the probability of correctly assigning observations to their predetermined groups. ${ }^{17}$

\section{RESULTS AND DISCUSSION}

Figure 1 shows the average photoacoustic signal from 4000 to $400 \mathrm{~cm}^{-1}$ of two conventional and genetically modified soybean pairs: Fig. 1a, transgenic BRS 244RR and Fig. 1b, conventional EMBRAPA 59; and Fig. 1c transgenic BRS 245RR and Fig. 1d, conventional BRS 133. The indicated ten peaks correspond to neutral lipids, proteins, carbohydrates, amide I, and amide II of the seed. ${ }^{18}$ Table I indicates their wavenumbers, functional groups, and modes of vibration. 
TABLE I. Identification of the wavenumber, functional groups, and modes of vibration of conventional and genetically modified soybean seeds.

\begin{tabular}{|c|c|c|c|}
\hline Peak & $\begin{array}{l}\text { Wavenumber } \\
\left(\mathrm{cm}^{-1}\right)\end{array}$ & Functional group & Mode of vibration \\
\hline 1 & $\sim 3330$ & $\mathrm{~N}-\mathrm{H}$ (protein) & Stretching \\
\hline 2 & 3008 & $=\mathrm{C}-\mathrm{H}$ cis (unsaturated lipids) & Stretching \\
\hline 3 & 2923 & $\begin{array}{l}-\mathrm{C}-\mathrm{H}\left(\mathrm{CH}_{2}\right) \text { (neutral lipids, } \\
\text { protein and carbohydrates) }\end{array}$ & Stretching asymmetric \\
\hline 4 & 2854 & $\begin{array}{l}-\mathrm{C}-\mathrm{H}\left(\mathrm{CH}_{2}\right) \text { (neutral lipids, } \\
\text { protein and carbohydrates) }\end{array}$ & Stretching symmetric \\
\hline 5 & 1747 & $-\mathrm{C}=\mathrm{O}$ (lipid ester) & Stretching \\
\hline 6 & 1652 & $\mathrm{C}=\mathrm{O}, \mathrm{C}-\mathrm{N}$ (amide I, protein) & Stretching \\
\hline 7 & 1542 & N-H (amide II, protein) & Bending \\
\hline 8 & 1457 & $\begin{array}{r}\mathrm{CH}_{2} \text { and } \mathrm{CH}_{3} \text { (neutral lipids, } \\
\text { protein and carbohydrates) }\end{array}$ & Bending scissoring \\
\hline \multirow[t]{2}{*}{9} & 1238 & $-\mathrm{C}-\mathrm{O}$ (fat) & Stretching \\
\hline & & $-\mathrm{CH}_{3}$ (fat) & Bending \\
\hline \multirow[t]{3}{*}{10} & 1157 & $-\mathrm{C}-\mathrm{O}$ (fat) & Stretching \\
\hline & & $-\mathrm{CH}_{2}-$ (fat) & Bending \\
\hline & & $\mathrm{C}-\mathrm{N}$ (protein) & Stretching \\
\hline
\end{tabular}

Although the intensities of these peaks can contribute significantly to this study, visual inspection of the spectra in Fig. 1 did not reveal considerable visible differences between them. As an example of the difficult interpretation, the broad band of $\mathrm{OH}$ centered on $3360 \mathrm{~cm}^{-1}$ overlaps with bands of other components, such as the $\mathrm{N}-\mathrm{H}$ stretching at $3330 \mathrm{~cm}^{-1}$ present in amide; the $1747 \mathrm{~cm}^{-1}$ band corresponds to the lipid ester stretch of fat and appears to be identical for all samples; between 1470 and $1370 \mathrm{~cm}^{-1}$, the modes of vibration bending of the $\mathrm{CH}_{2}$ and $\mathrm{CH}_{3}$ are also present, but their exact identification is very difficult. Due to these and other difficulties in the spectra interpretation, the ten peaks were selected in order to discriminate between transgenic and conventional soybean seeds by carrying out CDA.

The results of CDA suggest significant differences between the soybean varieties (Wilk's lambda $=0.368 ; F_{(21,546)}=$ 10.845; $P<0.001)$. Statistically, seven peaks $(1,3,4,5,6,8$,

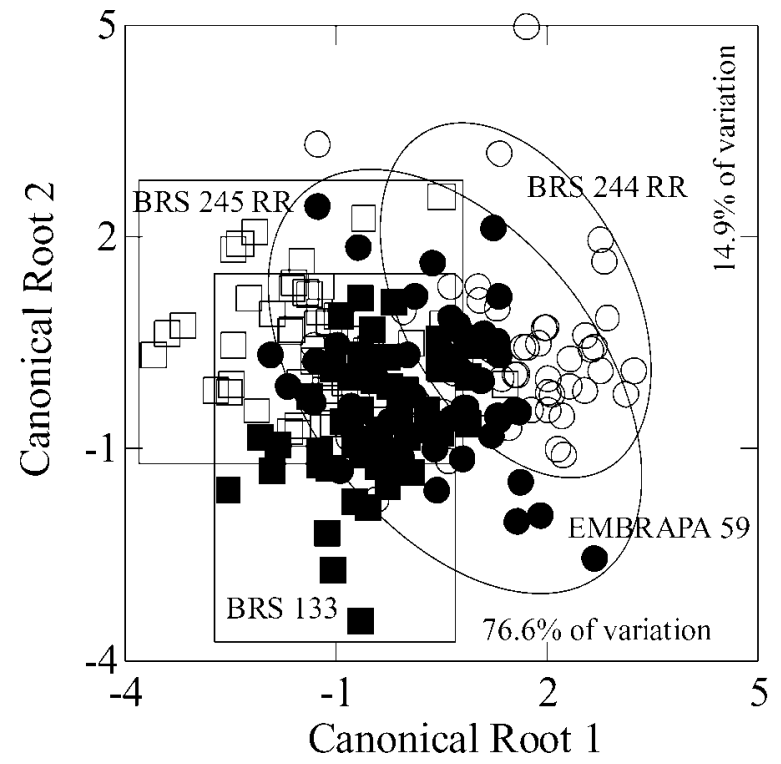

FIG. 2. Scatter plot of the first two canonical roots resulting from the canonical discriminant analysis applied to the 10 peaks listed in Table I.
TABLE II. Matrix of Mahalanobis distances between the two canonical roots obtained from the CDA applied to the $\mathbf{1 0}$ peaks listed in Table I.

\begin{tabular}{lcccc}
\hline & BRS 133 & BRS 244RR & EMBRAPA 59 & BRS 245RR \\
\hline BRS 133 & 0.00 & & & \\
BRS 244RR & $4.62^{\mathrm{a}}$ & 0.00 & & \\
EMBRAPA 59 & $1.51^{\mathrm{a}}$ & $2.24^{\mathrm{a}}$ & 0.00 & \\
BRS 245RR & $2.06^{\mathrm{a}}$ & $7.68^{\mathrm{a}}$ & $3.45^{\mathrm{a}}$ & 0.00 \\
\hline
\end{tabular}

a Significant to 0.001 .

and 9 in Table I) can be used to separate the varieties. The 3330 and $2923 \mathrm{~cm}^{-1}$ peaks are the best group soybean predictors in the first canonical root, while the peaks at 2854 and $1747 \mathrm{~cm}^{-1}$ are the best predictor in the second canonical root. Figure 2 shows the first two canonical roots, which explain $91.5 \%$ of the variance between soybean varieties, with the first and second canonical roots explaining $76.6 \%$ and $14.9 \%$ of the data variation, respectively. Only these two canonical roots were used to interpret our results. In order to quantify the difference between the studied varieties, the Mahalanobis distances were calculated and are exhibited in Table II. It is easy to observe that all pair-wise comparisons exhibited significant differences between varieties, with $B R S 245 R R$ and $B R S$ 244RR showing the largest differences between them.

Among the peaks in the first canonical root, the $3330 \mathrm{~cm}^{-1}$ peak in $B R S 245 R R$ has higher intensity value than $B R S$ $244 R R$. On the other hand, the $2923 \mathrm{~cm}^{-1}$ peak intensity has higher values in $B R S 244 R R$ than $B R S 245 R R$ once they are negatively correlated. For the second canonical root, the peak at $2854 \mathrm{~cm}^{-1}$ for $B R S 244 R R$ has a higher intensity than $B R S$ 133 , and the $1747 \mathrm{~cm}^{-1}$ peak presents an inverse pattern, with higher values in $B R S 133$ and lower values in $B R S 244 R R$.

\section{CONCLUSION}

In conclusion, the FT-IR-PAS method combined with CDA analysis was capable of distinguishing between the pairs $B R S$ $245 R R-B R S 133$ and BRS 244RR-EMBRAPA 59 in a comparative analysis, directly in the grain. Unsaturated and neutral lipids, proteins, and carbohydrates (3330 and 2923 $\mathrm{cm}^{-1}$ ) were the most important functional groups in the process of discrimination of the four soybean varieties. Our results show the potential of this methodology; however, for an effective application, studies involving a large number of pairs and different environments are necessary.

\section{ACKNOWLEDGMENTS}

The authors would like to thank FINEP and CNPq for their partial financial support.

1. K. B. Urbanek, B. M. Fonberg, R. D. Sawilska, P. Badowski, and M. Jedra, Rocz. Panstw. Zakl. Hig. 52, 313 (2001).

2. G. M. Brett, S. J. Chambers, L. Huang, and M. R. A. Morgan, Food Control 10, 401 (1999).

3. J. W. Stave, Food. Control 10, 367 (1999).

4. Y. Bertheau, A. Diolez, A. Kobilinsky, and K. Magin, J. Assoc. Anal. Chem. Int. 85, 801 (2002).

5. T. Giovannini and L. Concillo, Starch 54, 321 (2002).

6. S. A. Roussel, C. L. Hardy, C. R. Hurburgh, and G. R. Rippke, Appl. Spectrosc. 55, 1425 (2001).

7. K. Emura, S. Yamanaka, H. Isoda, and K. N. Watanabe, Breeding Sci. 56, 399 (2006).

8. L. H. C. Andrade, P. G. Freitas, B. G. Mantovani, M. S. Figueiredo, R. A. Lima, S. M. Lima, M. A. S. Rangel, and R. M. Mussury, "Detection of 
Soybean Rust Contamination in Soy Leaves by FTIR Photoacoustic Spectroscopy", Eur. Phys. J. ST, paper in press (2007).

9. J. Irudayaraj, S. Sivakesava, S. Kamath, and H. Yang, J. Food Sci. 66, 1416 (2001).

10. S. H. Gordon, R. W. Jones, J. F. McClelland, D. T. Wicklow, and R. V. Greene, J. Agric. Food Chem. 47, 5267 (1999).

11. S. Sivakesava and J. Irudayaraj, J. Sci. Food Agric. 80, 1805 (2000).

12. K. H. Michaelian, Photoacoustic Infrared Spectroscopy (John Wiley and Sons, New Jersey, 2003).

13. D. P. Almond and P. M. Patel, Photothermal Science and Techniques (Chapman and Hall, London, 1996).
14. L. F. L. Reis, M. V. Sluys, R. C. Garratt, H. M. Pereira, and M. M. Teixeira, An. Acad. Bras. Cienc. 78, 667 (2006).

15. M. F. Alibhai and W. C. Stallings, Proc. Natl. Acad. Sci. U.S.A. 98, 2944 (2001).

16. R. M. Zablotowicz and K. N. Reddy, Crop Protection 26, 370 (2007).

17. G. P. Quinn and M. J. Keough, Experimental design and data analysis for biologists (Cambridge University Press, Edinburgh, 2005), p. 537.

18. B. C. Smith, Infrared Spectral Interpretation: A Systematic Approach (CRC Press, New York, 1999), p. 265. 